\title{
Threshold Concepts in Literary Studies
}

\begin{abstract}
This essay proposes a series of "threshold concepts" for literary studies: text, meaning, context, form, and reading. Each term carries both commonsense understandings and disciplinary understandings, which differ from each other drastically. The disciplinary understandings entail far "more" than the commonsense ones. Unless such differences are named and explained clearly, unacknowledged commonsense understandings may hinder students' ability to learn equally unacknowledged disciplinary understandings. The naming and describing of such contrasting sets of understandings and of the differences between them is an act of disciplinary introspection-a scholarly and pedagogical act vital for understanding and teaching any complex body of knowledge. In addition to proposing threshold concepts for literary studies specifically, then, this essay encourages and offers a model for teacherscholars in any discipline to undertake the same disciplinary work of mapping out where we stand, where our students stand, and what difficulties lie between.
\end{abstract}

\section{KEYWORDS}

Threshold concepts, literary studies, disciplinary introspection, expert blind spot, commonsense, Lucille Clifton

"Okay, but I'm looking for ... more," I often want to tell my students when they respond too briefly or too superficially to a literary text, whether in class discussion or a journal entry or an essay. What do I mean by "more"? Well, that is the rub. It is hard to say. It is not just that I want students to write or speak more words about the text, though often that is part of it. I want their words to have more complexity, more nuance, more insight, more depth, more critical and creative thought, more attention to the details of the text and to the contexts in which those details exist. I recognize this sort of "more" when I see it-and especially when I do not. But it is difficult to describe with sufficient specificity for students to grasp why they have not produced it or how they could without being reductive ("quote from the text," "use literary terms"). My students might suspect I do not really know what I want. They would be half right. I do know, but tacitly. Through years of acculturating into literary studies, I have internalized rich disciplinary understandings of what literature is and what we are to do in reading and discussing it. What has become intuitive to me, however, is often counterintuitive to students. "More what, exactly?" they should ask.

As Jennifer Heinert and Nancy L. Chick (2016) observe, even apparently plain terms like "interpretation and analysis" often mean something different to teachers than to students (p. 323). To teach is "to bridge" the "gap" between our understanding and our students' understanding. "We have to help students transform how they think about, read, understand, and react to literary texts," Heinert and 
Chick propose, "by first rendering more accessible how we think about, read, understand, and react to literary texts. Only then will we teach students how to grow in the discipline" (p. 324). Such an approach to teaching literature - generous toward students, reflexive toward ourselves - makes visible our disciplinary "moves" for analyzing and arguing and our processes for reading and writing: the ways we reread, write in the margins, ask probing questions, attend to details, look for patterns, revise initial interpretations, and so forth. Teaching students howwe work with texts goes a long way, as a growing number of teachers and scholars attest (Blau, 2003; Graff, 2004; Harris, 2003; Showalter, 2009; Chick, Hassel, \& Haynie, 2009; Linkon, 2011; Corrigan, 2013/2014; Weissman, 2016; Wolfe \& Wilder, 2016). At the same time, I propose, we should also make visible the foundational, disciplinary understandings underlying these ways we work with texts - the why beneath the how.

The emerging theory of "threshold concepts" in higher education works to name the gaps between us and our students regarding the foundational understandings of our disciplines. In a frequently cited passage, Jan H. F. Meyer and Ray Land (2006, p. 3) explain:

A threshold concept can be considered as akin to a portal, opening up a new and previously inaccessible way of thinking about something. It represents a transformed way of understanding, or interpreting, or viewing something without which the learner cannot progress. As a consequence of comprehending a threshold concept there may thus be a transformed internal view of subject matter, subject landscape, or even world view. This transformation may be sudden or it may be protracted over a considerable period, with the transition to understanding proving troublesome. Such a transformed view or landscape may represent how people "think" in a particular discipline or how they perceive, apprehend, or experience particular phenomena within that discipline (or more generally).

In addition to being "transformative," threshold concepts can be "troublesome"-messy, slow, difficult to learn (Meyer \& Land, 2006, pp. 7, 8). Some threshold concepts are inherently complicated. Others may require a great deal of prior knowledge. Others may conflict with students' political or religious beliefs. Still others are difficult because they "render previously 'familiar' concepts strange" (Meyer \& Land, 2003, p. 420). As students grasp transformative, troublesome threshold concepts in literary studies, they begin to understand literature, and perhaps the world, from a disciplinary perspective. They begin not only to read and write like literary scholars but also to see and think like literary scholars.

Threshold concepts have recently made waves across English studies. In Toward an Inclusive Creative Writing: Threshold Concepts to Guide the Literary Writing Curriculum, Janelle Adsit (2017) pitches a robust lineup of threshold concepts for creative writing studies, including attention, authorship, creativity, craft, and others. In Naming What We Know: Threshold Concepts of Writing Studies, edited by Linda Adler-Kassner and Elizabeth Wardle (2015), a collective of leading scholars lay out a thorough set of threshold concepts for writing studies, including "Writing Is a Social and Rhetorical Activity," "Writing Speaks to Situations through Recognizable Forms," "All Writers Have More to Learn," and others (also see Pope-Ruark, 2011; Adler-Kassner, Majewski, \& Koshnick, 2012; Gogan, 2013; Sullivan, 2017; Sweeney, 2018). Discussions of threshold concepts in literary studies have been far more cursory, often no more than a blog post, a slide show, or an aside in a scholarly article largely about another topic. Suggested threshold concepts for literary studies comprise an unwieldy list, including 
signification, deconstruction, irony (Meyer \& Land, 2005, 2006), literary analysis (Heinert \& Chick, 2016), ethical reading (Irvine \& Carmichael, 2009), prosody (Murray, 2012), author, work, genre, period, close reading, interpretation, context, culture (Mazella, 2011,) the concept that texts "can sustain multiple, simultaneous interpretations" (Johnson, 2015), difference, reflection, and the process of "adjudicating" between competing interpretations (Day, 2007). In several documents, Gina Wisker and her colleagues offer the most sustained discussions of threshold concepts in literary studies, adding metaphor, intertextuality, ideology, and inquiry to the list (Wisker, Cameron, \& Antoniou, 2008; Wisker \& Robinson, 2009; Wisker, 2007, 2015). In her most refined effort to date, Wisker (2015) lifts up representation, context, formal expression, and interpretation as the "main threshold concepts of English literature teaching and learning" (pp. 6-7).

Building on these suggestions, I propose a set of five foundational, interrelated, teachable threshold concepts that could be particularly useful for helping students grasp the "more" we look for. Disciplinary understandings of text, meaning, context, form, and reading underlie all of the work we do in literary studies. When we continually ask students, for instance, to return to the text, to attend to the text, to read the text carefully or closely, we have a particular, disciplinary understanding of what kind of a thing a text is, what kind of an act reading is, what sort of role context and form play in meaning, what meaning itself is - understandings that differ, sometimes sharply, from the way most other folks understand these terms. Students need to cross the conceptual threshold where their very understanding of what a text is changes in order to read, write, and think about literature in a disciplinary way. Once students understand these concepts in a disciplinary way, the whole work of analyzing literature-and their professors' instance on "more" - may finally "make sense." Moreover, in laying bare the roots of that more, these threshold concepts also reveal one of the greater values that the study of literature offers. The richness of these concepts gestures toward a much richer, fuller, more complex world than we may otherwise have realized.

Although expansive disciplinary notions of these concepts may be difficult for some students to wrap their minds around, what makes the concepts troublesome is mostly not that they are hard to understand but that there are obstacles in the way, obstacles keeping both teachers and students from seeing the way each other sees. First, for most people outside of literary studies, these terms indicate straightforward and deeply established concepts borne out by extensive experience reading documents, watching movies, listening to songs, telling stories, coming across poems, and so forth. In literary studies, disciplinary understandings certainly "render previously 'familiar' concepts strange” (Meyer \& Land, 2003, p. 420). These prior understandings can easily prevent students from learning disciplinary understandings, particularly if the contrasting understandings are never directly addressed. Second, as teachers, disciplinary understandings can become so familiar to us that the commonsense understandings start to seem strange. We can come to know what we know so well that we forget that we know it and, as a result, have a hard time being aware of or imagining what it might be like for our students to not know it. Our expertise can lead to an "expert blind [sic] spot" (Ambrose et al., 2010, p. 113). In this sense, the thresholds of these concepts must be crossed in both directions. It is not enough just to know our own disciplinary understandings. We also have to remember how they differ from commonsense ones. To help students get from where they are to where we are, we have to understand both places and the terrain between. In the following sections, then, I contrast disciplinary and commonsense understandings of each of the terms I have proposed. 
The descriptions I offer are, admittedly and purposefully, impressionistic - based on the impressions I have gathered both from working with students and from participating in the discipline of literary studies over many years. In a parallel project, explaining to students the "moves" of academic writing, Joseph Harris (2006) suggests that the "drawback" of this kind of inquiry "is not that it is likely to be idiosyncratic but the reverse - that I may end up simply rehashing" what a particular group already knows. Of course, as he continues, that is not really a drawback when the whole purpose is "to articulate part of 'what goes without saying"' among that group (p. 4). Here, I want to rehash what goes without saying among many literary scholars and among many of those who are not literary scholars. At the same time, I realize that I describe what I take to be widely shared perspectives, not universally held ones, and that I filter them through my own perspective. Nonetheless, I expect my descriptions to be useful even for those teachers who see these concepts differently or who would choose different concepts; I offer my descriptions not just for the sake of promoting these specific descriptions but also for the sake of promoting the broader pedagogical and scholarly work these descriptions reflect.

Although current pedagogical scholarship, particularly in the scholarship of teaching and learning movement, stresses the importance of analyzing evidence of student learning in carefully and, thus, narrowly defined inquiries in order to move us beyond anecdote and lore in our understanding of teaching (Chick, 2018), we still also need to step back and reflect on our disciplines in broader ways. In this essay, I am stepping back, remembering, reflecting, and trying to convey the big picture. I am practicing an act of disciplinary introspection. Such disciplinary introspection should undergird and inform other kinds of pedagogical inquiry - including the work of designing and testing teaching strategies, gathering evidence of student learning, and so forth. In this essay, then, I encourage teacherscholars both in literary studies and in other disciplines to undertake the work of disciplinary introspection and I offer an example of what it might look like to do so.

For the sake of illustration, I apply each of the threshold concepts that I propose to the short, powerful, playful poem "wishes for sons" by the contemporary US poet Lucille Clifton. I encourage readers before proceeding to take a moment to read the poem, readily available both in The Collected Poems of Lucille Clifton and, through a quick internet search, on the websites of the Poetry Foundation (poetryfoundation.org), the Academy of American Poets_(poets.org), and elsewhere.

\section{"TEXT" AS A THRESHOLD CONCEPT}

In a commonsense understanding, a text holds little importance in and of itself. The text itself matters far less than what a writer intended it to convey. Intended thoughts and feelings take priority, not the way the text expresses them. A clearly written text is more or less transparent. Once readers see through the text to the meaning behind it, the text itself may be safely disregarded. Context and reading are likewise ancillary. Like a wheelbarrow, texts are tools for hauling meaning, preferably undamaged and unsullied, from writers' minds to readers' minds. While some texts are more or less clunky or leaky or shiny than others, the form of a text, how it is written, only affects how smoothly or reliably or eloquently it hauls the meaning — not what the text's meaning is or whether hauling a meaning is what the text is even for.

Coming to Lucille Clifton's “wishes for sons” with this sort of commonsense understanding of text, we might take the poem to be, first and foremost, a statement. In this poem, the poet states her thoughts and feelings about menstruation and menopause and about the relationship between women 
and men. Once we understand the poem as a statement, all we have to do is figure out what that statement states, its meaning.

In sharp contrast, a disciplinary understanding of text considers the text itself to hold utmost importance. The text-its particular shape, its particular wording - matters far more than whatever meaning the writer may or may not have intended. Intention is but one thing that goes into any text and but one thing that comes out (if, indeed, it comes out at all). If written artfully, the text will be as opaque as it is transparent. Readers look not behind but at the text for meaning. If a text expresses thoughts and feelings, those thoughts and feelings are inseparable from the way the text expresses them-its form. Far from incidental, the way the text is written, its shininess or clunkiness or leakiness, receives careful attention. The context and the act of reading a text likewise inescapably inform a text. Even after one meaning has been grasped, a text retains its importance because it inevitably holds still more possible meanings. Indeed, instead of being tools for conveying meaning, texts are arenas for generating meaning. Texts are less like wheelbarrows and more like gardens or vacant lots, not carrying a specified meaning but rather growing multiple meanings, often unanticipated, which proliferate, change, interact with the surroundings.

Such a disciplinary understanding would see "wishes for sons" not as a statement but as a movement. The poem does not merely (perhaps not even) express the poet's thoughts and feelings. Instead, through its words and forms, the text invites or stirs readers to participate in the making of meanings regarding the relationship between people of different genders, particularly with respect to menstruation and menopause. Once we understand "wishes for sons" as so much more than mere statement, we can begin taking part with the text in a mutual, ongoing, generative process of making meaning.

\section{"MEANING" AS A THRESHOLD CONCEPT}

In a commonsense understanding, texts communicate meaning. That is what they are for. The meaning of a text is not arbitrary or accidental or open to change but is determined already once it has been written down. A single text has a single meaning. The nature of that meaning is cognitive, not affective or effective; in other words, it is best understood as statement, not as experience or action. If everything goes well, the reader can say, "The text means such-and-such." Of course, there may be obstacles to getting to the meaning. Readers may lack the necessary vocabulary, or the text may come from too different a time or culture, or the way the text is written may be too complicated or unclear, too full of imagery, narrative, metaphor, and so forth (which some writers use to get the point across artistically, sometimes too artistically, rather than coming out and directly stating the meaning). Such obstacles, however, do not affect what the meaning of a text is. They are simply factors to navigate through to get to the meaning behind the text. Meaning is autonomous from context or form or the act of reading - autonomous even from the text itself. The meaning of the text is the thing the writer intends to say.

With this commonsense understanding, what does "wishes for sons" mean? We might say that with this poem Clifton is making a statement that, paraphrased, reads like this: Those who do not experience menstruation or menopause do not empathize with those who do the way they should-but if, somehow, they could, they would. Once we have this meaning, we are done with the text.

In contrast, a disciplinary understanding of meaning is far, far more expansive, not only 
regarding how meaning works in a text but also regarding what meaning even is. To begin with, a text not only may but almost certainly does have more than one meaning. Meaning is not a settled thing, somehow already fully determined by the time a text is written. Rather meaning is open to further unfolding over time and in new contexts, when a text is read from additional perspectives or when readers attend anew to previously neglected aspects of a text. Some of a text's meanings may be put, approximately, into the form of statements. But statements of what a text means always fall short of capturing the full meaning because meaning is not merely cognitive. Meaning is also affective and effective. What a text asks us to feel and what a text does are as much a part of meaning as what a text may say. The writer's intention influences meaning but does not determine it. Meaning is also, for instance, shaped by the material of the language itself - the way words and forms carry histories and resonances far beyond what a writer may be conscious of at the moment of putting words together. Meaning relies heavily on form as well. Any "difficulties" readers experience in getting to the meaning of a text do not obscure the meaning - they produce it. Additionally, the experience of readers reading and responding are parts of a text's meaning. Part of the meaning of a text also comes from whatever role it ends up playing in history - whether it goes into the literary canon or not, what it does to the lives of readers and writers, how it reflects or resists the many contexts it becomes part of.

With a disciplinary understanding of meaning, the question "What does the poem 'wishes for sons' mean?" does not really even make sense to ask, since the poem does not have a single, definite meaning that can be put into statement form. All the same, the poem is bursting with meaning and we can unpack a great deal of it. On a fairly surface level, yes, we could say that this poem states or, more accurately, implies that those who do not experience menstruation and menopause should be more empathetic and understanding toward those who do. That is part of the poem's meaning. But there is so much more. Other meanings may involve anger, humor, joy. The poem also comments on the process of aging, on the economics of the middle and lower classes, on the cultural meanings of menstruation and menopause, on those material aspects of contemporary US society that make menstruation and menopause painful and embarrassing, and on the long history of male physicians mistreating patients who have a uterus - all of which are, then, parts of the poem's meaning. The poem also takes part of its meaning from taking its place relative to literary history: rejecting the traditional use of capitalization means something, broaching traditionally taboo topics means something — both of which could take pages to unpack. What the poem might do to readers is also part of its meaning. If the poem angers or helps a male reader become more empathetic, or if the poem makes a female reader laugh or feel understood, or if the poem, eschewing gender labels except for a potentially ambiguous "sons," leaves a transgender or non-binary reader feeling included or excluded, then those experiences, too, are part of the poem's meaning. Once we grasp some of the meaning of "wishes for sons," we can just keep coming back for more.

\section{"CONTEXT" AS A THRESHOLD CONCEPT}

A commonsense understanding of context recognizes that a bit of information about the context in which a text was written can help readers understand the text. Relevant context consists primarily of background information on the text, including key details about the writer's life, beliefs, and culture and about major historical events taking place in the world when the text was written. Knowing the context of a text can reveal what a text means. Certain historical details can often make clear the significance of 
unfamiliar cultural references or the definitions of unknown words. At a larger scale, knowing about the writer's religious or political views could make clear the angle of a whole novel or play or poem. Sometimes, a text can also illuminate the context in which its stories are set, teaching readers about people and places far away or long ago.

Coming to "wishes for sons" with a commonsense understanding of context, readers would want to know that Clifton is a Black woman and a feminist who often writes about matters of race and gender, that she does in fact have sons of her own, and that she wrote the poem in the late twentieth century in the United States - a time and place when women, including African American women, had in living memory gained many rights while continuing to struggle for others. This background information reveals "wishes for sons" to be a feminist poem, expressing the poet's own political views and personal experiences, about the challenges women deal with in a society she views as continuing to be dominated by men.

A disciplinary understanding of context goes much farther, both in terms of how many and what kinds of contexts matter and in terms of how contexts and texts relate to each other. Yes, a writer's life, beliefs, culture, and identity (gender, race, class, sexuality, etc.) as well as the major historical events unfolding when a text is written are important contexts. But that kind of background information is just the beginning. Every text has innumerable, overlapping contexts-including personal, historical, cultural, literary, linguistic, political, scientific, philosophical, religious, and material contexts. Some specific contexts closest to a text include the histories of individual words in the text and of the text's genre and subject matter, the material conditions under which the writer wrote the text and the process through which the text was selected, edited, published, and distributed to its original readers, the responses of the original readers and of later readers and the process through which the text moved through time and place to its current readers, other texts written by the same writer and other texts that influenced the writer, theories and philosophies that apply to the text's subject, and even the current reader's own life and views and experience of the text. Any of these contexts could, potentially, shed light on a text's meaning. Taken together, these and other contexts form the very conditions of a text's existence. Any text is so deeply embedded in its contexts that text and context are, finally, inseparable. Texts are part of contexts and vice versa. The sheer number and complexity of contexts for any given text makes nailing down a single meaning for that text all the more impossible. If context elucidates some aspect of a text, then just as often it complicates other aspects. Context shapes meaning in ways too deep to either ignore or fully account for.

In what specific contexts does the poem "wishes for sons" exist? Among those with the most direct potential to illuminate the poem are the following, which I list at length to indicate something of just how expansive a disciplinary concept of context is:

- the popular feminist magazine Ms., where Clifton first published the poem, in 1991, accompanied by drawings;

- the history of quilting in light of the book (titled quilting) and section ("eight-pointed star") where Clifton collected the poem after its magazine publication;

- the social position of Black mothers in the United States in the late twentieth century;

- the history of male doctors providing inadequate care for patients who have a uterus, often stemming from ignorance and arrogance (see also: "mansplaining"); 
- the political and philosophical traditions of feminism and womanism, especially including ideas of the personal as political and of gender and race as social constructs;

- the writings of other contemporary US poets, including Langston Hughes, who published some of Clifton's first poems, and Ishmael Reed, another friend and influence of hers;

- the histories of multiple literary movements, including free verse poetry, lyrical poetry, confessional poetry, and the Black Arts Movement, and even - to understand the poem's brevity, use of first-person lyric, and volta-like ending, as well as its rejection of rhyme, meter, and capitalization — the sonnet;

- scholarship, criticism, and popular writing directly about Clifton's poetry by Scarlett Cunningham (2014), Alicia Ostriker (1993), Elizabeth Alexander (2010), and others;

- the biology of the uterus;

- the economics of "feminine hygiene products

- the historical and social significance of menstruation and menopause, including the longstanding social taboo against publicly discussing them, including in literature;

- other of Clifton's writings, particularly her other well-known poems on related subjects, "poem in praise of menstruation," "poem to my uterus," and "to my last period"; and

- other poems influenced by this poem or written in the cultural space it helped open, from Sharon Olds's (2016) recent "Ode to Menstrual Blood" and "Ode to the Female Reproductive System" to the hundreds of poems amateur poets have written on such subjects and posted to the internet.

Clifton's "wishes for sons" exists inextricably within these and many other contexts - a vast cocontextual web. Each context can illuminate the poem and, in turn, be illuminated by it. Each connection we explore between the poem and one of its contexts allows us to see the poem from a new perspective.

\section{"FORM" AS A THRESHOLD CONCEPT}

A commonsense understanding typically gives little thought, if any, to form. Only the most wellknown elements of form may even be noticed, such as "metaphor," "imagery," "meter," "poem," and so forth. Moreover, formal elements are primarily considered as decorative, as artistic flourishes that show off a writer's skill and make the text more pleasant or interesting to read. When aspects of form do convey meaning, it is meaning that could have been stated plainly but has been dressed up for effect. Pleasantries aside, form is ancillary to what the text is or means.

A commonsense reading of "wishes for sons" may well notice the lack of capitalization, the vivid imagery, and the repetition of " $i$ wish" and "let" and may well even note that these serve to catch and hold a reader's attention, give the poem a breaking-the-rules feeling, and create a rhythm. A commonsense reading might also look for "symbolism." Perhaps menstruation and menopause symbolize being a woman; perhaps the phrase "a strange town" symbolizes being lost or out of place. In this commonsense reading, however, less attention goes to how the poem is written than to what the poem says. 
In contrast, in a disciplinary understanding, form plays an expansive and integral role. Form encompasses not only those literary devices that have names but every aspect of a text that has been shaped or patterned (or formed) in some way, whether consciously or not. The form of a text is the how of how the text has been written. Form carries, enacts, generates meaning. The use of form in a text depends on readers' familiarity with the use of related forms in other texts, as when a narrative either follows or rejects familiar plot structures, creating different formal effects one way or the other. Certain uses of form stand out for readers to consciously interpret, as when a cheerful message comes wrapped in foreboding imagery, inviting readers to decipher the contrast between form and content. But whether overt or covert, form pervasively shapes readers' experience of a text. In this, how a text says what it says matters as much or more than whatever it says.

Reading "wishes for sons" with a disciplinary understanding of form reveals a great deal more about its form and entails the understanding that its form, to a significant degree, is the poem-its shape enacting its meanings. A disciplinary reading would note not only the poem's lack of capitalization, vivid imagery, repetition of "i wish" and "let," and how menstruation and menopause "symbolize" being a woman but many other aspects of form as well. As before, I list aspects of the poem's form in detail to gesture toward how expansive a disciplinary understanding of form is:

- the choice of a culturally "taboo" topic;

- ambiguity about whether the "wishes" are positive or negative;

- distinctive diction (using "sons" rather than "men"), "low-brow" cultural references ("tampon,, "7-11"), colloquial phrases ("like you wouldn't believe" and "someone special”), and plain, Anglo-Saxon words (“cramps," “clots," “week");

- use of a double negative ("not unlike");

- motif of time (“one week early," “one week late," "later," "then”);

- the poem's intimate, personal scale suddenly expanding to the scale of "arrogance in the universe," then returning to the personal;

- use of pronouns ("i” for the speaker, "they" for the sons, but no "you" for the poem's addressees);

- enjambment (the change of tone between "accepted" at the end of one line and "arrogance" at the beginning of the next) and end-stopped lines (several forceful oneline sentences);

- compression, the way the poem says a lot in a few short lines, implying larger narratives very briefly (i.e., the phrase "no 7-11" suggests a character, conflict, and setting), naming situations without naming the implications (i.e., someone down to "the last tampon" may have to improvise, bleed on their clothes, or risk toxic shock syndrome by using the tampon too long), and generally saying by way of not saying;

- patterns of sound, including anaphora ("i wish ... i wish ... i wish") and other repeated words (i.e., the pattern of "them," switched at the last line to "themselves"), alliteration ("accepted"/"arrogance," "town"/"tampon," "someone"/"special," and over a dozen words beginning with $\mathrm{w}$ ) and other repeated sounds (-own, -on, -en at the end of lines in the first stanza), the rhythm of shorter and longer sentences alternating, the rhythm of words of one and two syllables throughout the poem giving way, briefly near the end of the poem, to words of three and five syllables (including "gynecologists"), and regular 
use of iambs (in an unmetered poem) — all of which give the poem a musical quality of some intensity, suggestive, even, of incantation; and

- figurative language, both with clots personified as able to "want" and with the poem's small, particular instances serving as metonymy for larger, more general social situations (i.e., cramps, a closed store, a love interest, and a gynecologist standing in for larger personal and social dynamics).

Through these and other formal aspects of the poem, Clifton invites, entices, and provokes readers to vicariously experience or re-experience some of the painful dynamics of having a uterus in this society, to try on the edginess of transgressing social norms, to get caught up and pulled along by the incantation of the poem's repetitions and rhythms, and to feel, in the poem's final shift, either a cutting critique or an affirmation of past experience or an invitation to change. Each formal aspect we notice in the poem allows us a better sense of how the poem works, what its fuller meanings are.

\section{"READING" AS A THRESHOLD CONCEPT}

A commonplace understanding of reading could hardly be plainer. Reading means accessing the meaning that the writer intends to express through the words of the text. To accomplish this task, a reader looks at the words and sentences in the order they are written and decodes what each means, line by line, page to page. Unfamiliar words should be looked up or figured out through context clues. Finally, after reading, it is beneficial to sum up the overall meaning of the text, to see what the words and sentences all add up to. In a sense, what reading is and how one reads do not change, fundamentally, after primary school. Of course, readers may encounter increasingly difficult texts, with higher levels of vocabulary, complexity, and subject matter. But the task of reading — and the methodremain the same. Any difficulties encountered while reading signal problems with either the clarity of the text or the ability of the reader.

To read "wishes for sons" with a commonsense understanding of reading would mean starting with the title, moving to the first line, and moving line by line to the end, decoding what each word means along the way: " $i$ " is a first person pronoun referring to the person speaking, "wish" means to actively want or hope for something, "them" is a third person pronoun referring back to the "sons" of the title and, probably, to men in general, "cramps" refers to abdominal pain experienced during menstruation, and so on. By the end, the reader might come to a sense of the meaning of the poem as a whole-how the poet wishes unpleasant experiences on men so men can realize their arrogance toward others and develop empathy. And that is about it. The poem has now been read.

Again, a disciplinary understanding of reading differs greatly from a commonsense one. To begin with, readers can read in many ways. Decoding the words of a text to figure out the writer's intended meaning is only one way of reading. To stop there is to read superficially. Reading deeply means participating with a text in making meaning. Active, engaged, creative, and critical ways of reading are especially valued: grabbing hold of a text to work with it, attending carefully to details, asking questions, making connections among different passages or between the text and other texts and other life experiences, rereading passages or a whole text several times, purposefully looking for things that do not make sense or do not quite fit, reading with context and form in mind, reading with a particular personal, political, or philosophical perspective in mind, and writing on, annotating, underlining, and otherwise marking directly on the text. A disciplinary understanding of reading also 
attends to the experience of reading — what the words do to us or invite us to do-and even, sometimes, to reading as an embodied activity - whether readers read in a favorite chair, a coffee shop, or outdoors, in company or in solitude, while tired or rested, upset or at peace, looking at a screen or holding a book, aloud or silently, taking notes or lost in the text, focused or distracted. A disciplinary understanding of reading requires a text be read and reread from multiple perspectives, considering multiple possible interpretations. In each case, the meanings that emerge are understood to be profoundly shaped by the act of reading.

With a disciplinary understanding of reading, we may read "wishes for sons" in many different ways. To read critically, we may look for how deeper meanings lurk beneath obvious ones. We might zero in on the contradiction between the positive word "wishes" and the seemingly negative content of the wishes and ask whether the poem is a blessing or a curse or whether indeterminacy is the point. Or we might apply specific theoretical lenses, looking at the poem through feminist or queer theories about gender or through Marxist notions of materiality. Or we might consider the poem in context of other representations of medical doctors by African American women writers, such as Toni Morrison's (2012) novel Home. To read contemplatively, we may ask what "wishes for sons" asks of us as persons, whether we might become more aware or compassionate through its words. Or we might reflect silently on the poem when driving through a strange town or send a copy to a friend going through menopause. Or we might chant it or journal about it or paint in response to it. To read with an activist bent, we might read the poem to enlighten or energize ourselves - so that we may recognize sexism more acutely and resist it more fervently. Or we might pass the poem around in activist circles or read it aloud in safe spaces established for people who have experienced the kinds of things the poem describes. To read the poem from a creative writer's perspective, we might examine the craft of "wishes for sons," taking note of how Clifton uses alliteration and imagery, how she structures the poem to build in theme and sound from line to line, and we might consider what we might borrow of these techniques in our own writing. The possibilities for reading go on. Just as text and meaning are inexhaustible, so are the ways of making meaning with a text.

\section{"MORE" AS GENEROSITY}

All successful students and teachers of literature eventually internalize disciplinary understandings of such threshold concepts as text, meaning, context, form, and reading - often tacitly and on their own. However, by naming and describing and finding ways to teach threshold concepts directly, we may help students cross the thresholds more smoothly and quickly, with less time wasted blundering about trying to do the work of the discipline with inadequate, commonsense understandings and more time put to good use digging deeply into literary texts. More importantly, we may also help some students cross the thresholds who, if left to their own devices, might never do so. At the same time, the nature of these concepts is that they must be experienced and internalized to really be understood. Students can only understand these concepts when the concepts, whether explicitly or not, shape the way they see things in the world. This kind of transformation will not happen for most students just by us telling them about the concepts. In addition to direct instruction, then, we ought to create or watch for opportunities to help students along in those moments when they experience what these concepts explain: those moments when students run into the limits of their commonsense understandings; when students intuit from the work they are asked to do with texts or the feedback they receive or even from the texts themselves that there is more to literature than they yet understand; when students glimpse a 
richness at work in the habits and comments of their professors, of more advanced students, and of scholarly articles they may read; and when they study literary theory. If we pay attention to these opportunities and have at the ready language to explain to students the thresholds they find themselves at, we may well facilitate truly transformative learning.

So I end up back where I began. I am still looking for more from-and for-my students. But now I have more specific, thorough language to describe what that more means. But, for all its generality, more is an important term, too, to describe the overarching vision the threshold concepts of literary studies revolve around. The disciplinary love of more goes by many names: "complexity" (Fahnestock \& Secor, 1991), "difficulty" (Salvatori \& Donahue, 2005), the reason for "digging into literature" (Wolfe \& Wilder, 2016), the reason for "unpacking" texts (Chick, 2009), the expansive abundance at the center of literary studies. There is incredible generosity of vision here. For those used to understanding literary studies first and foremost through a hermeneutic of suspicion, this claim may seem counterintuitive. Habitually reading against the grain may not strike us as particularly generous. But it can be practiced that way. We can practice suspicion, skepticism, critical thinking, "doubting” (as in Peter Elbow's [1973] "doubting game") not for fear that the texts might otherwise pull a fast one on us but because these are practices of digging, probing, pushing to discover or create more. Besides, hermeneutics of suspicion are not the only way to read in literary studies anyway. There is more to the discipline than that-yet another generosity.

When students come to understand the threshold concepts of literary studies, they will learn to write and speak about literary texts with greater depth and sophistication. That is benefit enough. But there is more. As Meyer and Land (2006) explain, threshold concepts can change "how people 'think' ... perceive, apprehend, or experience ... within [a particular] discipline (or more generally)" (p. 3, emphasis added). When our students transform the way they understand literature, they may also transform the way they understand the world. As we help students to see that there is so much more to literature than they may realize, the literary texts they and we read generously can teach us all that our lives and the world we live in have this thickness, this abundance, too.

\section{INTROSPECTION ACROSS DISCIPLINES}

In describing threshold concepts in literary studies, I contribute to a larger project underway across disciplines - the work of disciplinary introspection, of contemplating and articulating, for the purpose of teaching, what our disciplines are and have to offer. Threshold concepts complement other forms of this inquiry, which valuably consider what we want students to do (e.g., Wiggins and McTighe, 2005) and what students have trouble doing (e.g., Pace, 2017). Threshold concepts contemplate the understandings underlying that doing and that trouble. Although we cannot observe our and our students' understandings and misunderstandings as directly as we can observe our actions, we may nonetheless intuit what they may be by attending broadly to our and others' experiences in the discipline, drawing on the four sources Stephen Brookfield (1995) taps for critically reflective teaching. We have spent years (1) working with students, (2) conversing with colleagues, and (3) learning our disciplines. Recalling and reflecting on these experiences, we can look for patterns of proverbial "ah ha" and "uh oh" moments when we and others either "got it" or did not. Recognizing those patterns and the threshold concepts that may attend them may take time, flashes of insight, or both. But in many disciplines, we do not have to start this process from scratch. We can draw on (4) a rapidly growing body of pedagogical scholarship. Mick Flanagan (2018), retired professor of electronic engineering, maintains 
an exhaustive bibliography of scholarship on threshold concepts, arranged by discipline. From accountancy to zoology, teachers may readily find and build on prior efforts at this form of disciplinary introspection.

The approach to threshold concepts I model in this essay stresses both sides of each threshold. On one side, we need to know where we teachers stand - which is what our students must come to understand in order to cross thresholds into our discipline. On the other side, we also need to know where our students stand-which is what we must come to understand in order to cross back over to where our students are to help them along. Christie Launius and Holly Hassel (2018) address both of these sides in Threshold Concepts in Women's and Gender Studies. After explaining each of the book's concepts, they unpack misunderstandings students commonly hold, picked up from antifeminist messages present in popular culture and elsewhere (also see Hassel and Launius 2017). In contrast, in literary studies, the key obstacles students face may not be misunderstandings as much as different understandings, picked up from the everyday use of the same terms outside of literary studies. My colleagues tell me the same gap attends such crucial terms in other disciplines as theory, research, critical, significant, myth, empathy, and others. In other cases, threshold concepts may be difficult to learn because they are complex or uncomfortable or for still other reasons. Whatever the obstacles in our discipline, once we find words to describe where we and our students stand and what difficulties lie between, we will be all the more equipped to guide our students forward.

Paul T. Corrigan teaches writing and literature at Southeastern University in Lakeland, Florida (USA). He is currently writing a book on the teaching of the reading of literature. He writes and edits a blog at teachingandlearninginhighered.org.

\section{REFERENCES}

Adler-Kassner, L., Majewski, J., \& Koshnick, D. (2012). The value of troublesome knowledge: Transfer and threshold concepts in writing and history. Composition Forum, 26. Retrieved from http://compositionforum.com/issue/26/troublesome-knowledge-threshold.php

Adler-Kassner, L., \& Wardle, E. A. (Eds.). (2015). Naming what we know: Threshold concepts of writing studies. Logan, UT: Utah State University Press.

Adsit, J. (2017). Toward an inclusive creative writing: Threshold concepts to guide the literary writing curriculum. London: Bloomsbury Academic.

Alexander, E. (2010, February 10). Remembering Lucille Clifton. The New Yorker. Retrieved from http://www.newyorker.com/books/page-turner/remembering-lucille-clifton

Ambrose, S. A., Bridges, M. W., DiPietro, M., Lovett, M. C., \& Norman, M. K. (2010). How learning works: Seven research-based principles for smart teaching. San Francisco, CA: Wiley.

Blau, S. D. (2003). The literature workshop: Teaching texts and their readers. Portsmouth, NH: Heinemann.

Brookfield, S. (1995). Becoming a critically reflective teacher. San Francisco, CA: Jossey-Bass.

Chick, N. L. (2009). Unpacking a signature pedagogy in literary studies. In R. Gurung, N. L. Chick, \& A. Haynie (Eds.), Exploring signature pedagogies: Approaches to teaching disciplinary habits of mind (pp. 36-55). Sterling, VA: Stylus.

Chick, N. L., Hassel, H., \& Haynie, A. (2009). "Pressing an ear against the hive": Reading literature for complexity. Pedagogy, 9(3), 399-422. https://doi.org/10.1215/15314200-2009-003

Chick, N.L. (2018). The SoTL Guide. Retrieved from https://nancychick.wordpress.com/sotl-guide/

Clifton, L. (2012). The Collected Poems of Lucille Clifton 1965-2010. K. Young \& M. S. Glaser (Eds.). Rochester, NY: BOA Editions.

Corrigan, P. T. (2013/2014). Attending to the act of reading: Critical reading, contemplative reading, and active reading. Reader: Essays in Reader-Oriented Theory, Criticism, and Pedagogy, 65/66, 146-173.

Cunningham, S. (2014). The limits of celebration in Lucille Clifton's poetry: Writing the aging woman's body. Frontiers, 35(2), 30-58. https://muse.jhu.edu/article/552625/ 
Day, H. (2007). Helicopters, jigsaws, and plaits: Revealing the hidden language and literature curriculum. Pedagogy, 7(3), 534-543. https://doi.org/10.1215/15314200-2007-013

Elbow, P. (1973). Writing without teachers. New York, NY: Oxford UP.

Fahnestock, J., \& Secor, M. (1991). The rhetoric of literary criticism. In C. Bazerman \& J. Paradis (Eds.), Textual dynamics of the professions: Historical and contemporary studies of writing in professional communities ( $\mathrm{pp}$. 76-96). Madison, WI: University of Wisconsin Press.

Flanagan, M. (Ed.). (2018). Threshold concepts: Undergraduate teaching, postgraduate training, professional development and school education. A short introduction and a bibliography. Retrieved from https://www.ee.ucl.ac.uk/ mflanaga/thresholds.html

Gogan, B. (2013). Reading at the threshold. Across the Disciplines, 10(4), 1-21. Retrieved from https://wac.colostate.edu/docs/atd/reading/gogan.pdf

Graff, G. (2004). Clueless in academe: How schooling obscures the life of the mind. New Haven, CT: Yale University Press.

Harris, J. (2003). Revision as a critical practice. College English, 65(6), 577-592. Retrieved from https://dukespace.lib.duke.edu/dspace/bitstream/handle/10161/6953/Revision.pdf?sequence=1

Harris, J. (2006). Rewriting: How to do things with texts. Logan, UT: Utah State University Press.

Hassel, H. \& Launius, C. (2017). Crossing the threshold in introductory women's and gender studies courses: An assessment of student learning. Teaching \& Learning Inquiry, 5(2), 30-46. https://doi.org/10.20343/teachlearninqu.5.2.4

Heinert, J., \& Chick, N. L. (2016). Reacting in literary studies: Crossing the threshold from quality to meaning. Arts \& Humanities in Higher Education, 16(3), 320-30.

Irvine, N., \& Carmichael, P. (2009). Threshold concepts: A point of focus for practitioner research. Active Learning in Higher Education, 10(2), 103-19. https://doi.org/10.1177/1469787409104785

Johnson, A. (2015). Thresholds of interpretation: Identifying, producing, and supporting with The Turn of the Screw. CEA Critic, 77(2), 196-210. https://muse.jhu.edu/article/587917

Launius, C. and Hassel, H. (2018). Threshold concepts in women's and gender studies: Ways of seeing, thinking, and knowing (2nd ed.). New York, NY: Routledge.

Linkon, S. L. (2011). Literary learning: Teaching the English major. Bloomington, IN: Indiana University Press.

Pace, D. (2017). The decoding the disciplines paradigm: Seven steps to increased student learning. Bloomington, IN: Indiana University Press.

Pope-Ruark, R. (2011). Know thy audience: Helping students engage a threshold concept using audience-based pedagogy. International Journal for the Scholarship of Teaching and Learning, 5(1), 1-16. Retrieved from http://w3.georgiasouthern.edu/ijsotl/v5n1/articles/PDFs/ Pope-Ruark.pdf

Mazella, D. (2011, October 8). How might the notion of the "threshold concept" be applied to cultural studies? (response to Kathryn Temple). The Long Eighteenth [Web log post]. Retrieved from https://long18th.wordpress.com/2011/10/08/how-might-the-notion-of-the-threshold-concept-beapplicable-to-cultural-studies/

Meyer J. H. F., \& Land R. (2003). Threshold concepts and troublesome knowledge: Linkages to ways of thinking and practising within the disciplines. In C. Rust (Ed.). Improving student learning theory and practice-Ten years on: Proceedings of the 2002 10th International Symposium Improving Student Learning (pp. 412-424). Oxford, UK: Oxford Centre for Staff and Learning Development.

Meyer, J. H. F., \& Land, R. (2005). Threshold concepts and troublesome knowledge (2): Epistemological considerations and a conceptual framework for teaching and learning. Higher Education, 49(3), 373388. http://dx.doi.org/10.1007/s10734-004-6779-5

Meyer, J. H. F., \& Land, R. (2006). Threshold concepts and troublesome knowledge: An introduction. In J. H. F.

Meyer \& R. Land (Eds.), Overcoming barriers to student understanding: Threshold concepts and troublesome knowledge (pp. 3-18). New York, NY: Routledge.

Morrison, T. (2012). Home. New York: Knopf.

Murray, S. (2012, June). A Shakespeare threshold: Engaging students in understanding prosody. Paper presented at the Fourth Bienniel Conference on Threshold Concepts: From Personal Practice to Communities of Practice, Trinity College, Dublin.

Olds, S. (2016). Odes. New York: Knopf. 
Ostriker, A. (1993). Kin and kin: The poetry of Lucille Clifton. American Poetry Review, 22(6), 41-48. https://www.jstor.org/stable/27781336

Salvatori, M. R., \& Donahue, P. (2005). The elements (and pleasures) of difficulty. New York, NY: Pearson Longman. Sullivan, P. (2017). "Deep reading" as a threshold concept in composition studies. In P. Sullivan, H. Tinberg, \& S. Blau (Eds.), Deep reading: Teaching reading in the writing classroom (pp. 143-71). Urbana, IL: National Council of Teachers of English.

Showalter, E. (2003). Teaching literature. Malden, MA: Blackwell.

Sweeney, M. A. (2018). Audience awareness as a threshold concept of reading: An examination of student learning in biochemistry. Research in the Teaching of English, 53(1), 58-79. http://www.ncte.org/journals/rte/issues/v53-1

Weissman, G. (2016). The writer in the well: On misreading and rewriting literature. Columbus, OH: Ohio State University Press.

Wiggins, G. and McTighe, J. (2005). Understanding by design (expanded 2nd ed.). Alexandria, VA: Association for Supervision and Curriculum Development.

Wisker, G. (2007). Crossing liminal spaces: Teaching the postcolonial gothic. Pedagogy, 7(3), 401-425. https://doi.org/10.1215/15314200-2007-007

Wisker, G. (2015). Teaching literature: Contemporary gothic, threshold concepts, social justice and dialogue. York, UK: Higher Education Academy. Retrieved from https://www.heacademy.ac.uk/knowledge-hub/teachingliterature-contemporary-gothic-threshold-concepts-social-justice-and-dialogue

Wisker, G., Cameron, S., \& Antoniou, M. (2008). Connotations and conjunctions: Threshold concepts, curriculum development, and the cohesion of English studies. Higher Education Academy English Subject Centre Project. Retrieved from https://www.heacademy.ac.uk/knowledge-hub/connotations-andconjunctionsthreshold-concepts-curriculum-development-and-cohesion

Wisker, G., \& Robinson, G. (2009). Encouraging postgraduate students of literature and art to cross conceptual thresholds. Innovations in Education \& Teaching International, 46(3), 317-330. https://doi.org/10.1080/14703290903069035

Wolfe, J., \& Wilder, L. (2016). Digging into literature: Strategies for reading, analysis, and writing. Boston, MA: Bedford/St. Martins.

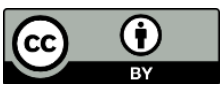

Copyright for the content of articles published in Teaching \& Learning Inquiry resides with the authors, and copyright for the publication layout resides with the journal. These copyright holders have agreed that this article should be available on open access under a Creative Commons Attribution License 4.0 International (https://creativecommons.org/licenses/by/4.0). The only constraint on reproduction and distribution, and the only role for copyright in this domain, should be to give authors control over the integrity of their work and the right to be properly acknowledged and cited, and to cite Teaching \& Learning Inquiry as the original place of publication. Readers are free to share these materials-as long as appropriate credit is given, a link to the license is provided, and any changes are indicated. 